\title{
INCLUSÃO E EDUCAÇÃO DE POPULAÇÕES EM SITUAÇÕES DE RISCO OU VULNERABILIDADE SOCIAL
}

\author{
INCLUSION AND EDUCATION OF POPULATIONS IN SITUATIONS \\ OF SOCIAL RISK OR VULNERABILITY
}

\section{Apresentação}

Esta proposta do número temático foi idealizada pela professora Dra. Adriana da Silva Thoma e sua publicação, de algum modo, é também parte de seu legado. Adriana foi uma pesquisadora dedicada à temática da inclusão, com uma inserção importante na Educação de Surdos e na Inclusão Escolar. Seu inesperado falecimento, em novembro de 2018, causou, a todos que tiveram a oportunidade de partilhar de sua convivência, uma grande tristeza. Contudo, Adriana não era uma pessoa de afetos tristes; sua generosidade, seu entusiasmo, sua disposição em acolher o outro - enfim, sua alegria diante da vida - seguem nos movimentando e fazendo-nos encontrá-la de outros modos.

Quando Adriana partiu, os textos que compõem este número temático já estavam escritos e compilados. Os(as) autores(as) entendem, assim, que sua publicação também é uma forma de homenagem. Dessa maneira, agradecemos imensamente aos Cadernos Cedes por possibilitarem que isso seja viabilizado.

Assim, este número temático tem como objetivo reunir artigos que resultem de investigações sobre inclusão e educação, com ênfase em políticas e práticas relacionadas a populações em situações de risco ou vulnerabilidade social. Para organizá-lo, convidamos pesquisadores que atuem em diferentes campos - particularmente em Educação e Psicologia - e estejam vinculados a instituições situadas em diferentes regiões do Brasil, bem como uma universidade argentina.

Para Carmo e Guizardi (2018), o conceito de vulnerabilidade relaciona-se a uma ideia de multideterminação de sua gênese, englobando não apenas a questão socioeconômica, mas também fragilidades afetivo-relacionais e desigualdade de acesso a serviços. Nessa perspectiva, as autoras apontam que a vulnerabilidade não se refere a uma condição natural, mas diz respeito a uma articulação entre situações individuais e coletivas, as quais podem ser modificadas.

A vulnerabilidade social daqueles que vivem em condições precárias, principalmente por fatores socioeconômicos, faz com que, muitas vezes, esses sujeitos dependam de programas de auxílio do Estado ou da assistência de instituições para garantirem sua sobrevivência e exercerem sua cidadania. Questões relacionadas a sujeitos ou grupos em situação de risco ou vulnerabilidade social têm sido objeto especialmente das políticas públicas de saúde e assistência social. As estratégias colocadas por essas políticas envolvem, frequentemente, práticas educativas. Muitas vezes, a escola acaba gerenciando as condições para que as políticas sejam efetivadas, bem como para que, por meio delas, a vulnerabilidade não resulte em processos e eventos de aumento de riscos para esses sujeitos. Diante disso, consideramos fundamental a realização de pesquisas em Educação que se proponham a problematizar tais questões, como fazem os autores dos artigos que compõem esta proposta.

O texto que abre o número temático, “A Judicialização da Inclusão: O Governo pela Lei”, de Adriana da Silva Thoma, Betina Hillesheim e Carolina de Freitas Corrêa Siqueira, 
pesquisadoras da Universidade Federal do Rio Grande do Sul (UFRGS) e da Universidade de Santa Cruz do Sul (UNISC), aborda o tema da judicialização da inclusão, compreendendo “judicialização" como ações desenvolvidas pelo Poder Judiciário, voltadas à inclusão de grupos em situação de risco ou vulnerabilidade social. A noção de governamentalidade biopolítica, na perspectiva de Michel Foucault, é utilizada nas análises para problematizar as estratégias que o Estado utiliza para regular os rumos da inclusão a partir de dois eixos que se articulam: o da fiscalização e da intervenção recomendatória e o da orientação, que toma a argumentação e o convencimento como formas de produzir modos de ser inclusivos.

O segundo artigo, "Competências e Direito de Aprendizagem: Protagonismo e Vulnerabilidade", de Carine Loureiro, Graciele Kraemer e Maura Corcini Lopes, da Universidade do Vale do Rio do Sinos (UNISINOS/RS), apresenta discussões sobre os resultados de uma pesquisa documental que analisa como a aprendizagem é definida nas políticas que fundamentam a estrutura curricular da educação brasileira. Segundo as autoras, as noções de aprendizagem por competências e de direitos de aprendizagem são centrais nas diretrizes educacionais na atualidade e fomentam o desenvolvimento de certo protagonismo por parte dos sujeitos, aumentando o quantitativo de indivíduos em condições de vulnerabilidade.

"Vulnerabilidade da População Negra e Políticas Educacionais no Brasil" é o tema do terceiro artigo, de Simone Maria Hüning, Aline Kelly da Silva e Tathina Lúcio Braga Netto, pesquisadoras da Universidade Federal de Alagoas (UFAL) e da Universidade Federal do Rio Grande do Sul (UFRGS). Percorrendo processos históricos que promoveram a marginalização e a vulnerabilidade da população negra brasileira, as autoras analisam documentos de políticas educacionais que tratam da inclusão de discussões raciais no currículo, do combate ao racismo e da redução de desigualdades étnico-raciais. No diálogo com Foucault, Agamben e Mbembe, entendem essas políticas como uma resposta estatal diante da vulnerabilidade social produzida, que expressa simultaneamente as conquistas e os tensionamentos na relação entre a população negra e o Estado.

Cintia Schwamberger e Silvia Grinberg, do Centro de Estudios Desigualdades, Sujetos e Insituciones (CEDESI), Escuela de Humanidades Universidad Nacional de San Martín (UNSAM)/Consejo de Investigaciones Científicas y Técnicas (CONICET), Buenos Aires, Argentina, são as autoras do quarto artigo, intitulado "Cuerpos que Importan en el Patio de Atrás. Precaridad y Hacer Escuela Especial en Contextos de Pobreza Urbana”. As autoras discutem as tensões dos processos de in/exclusão em escolas de educação especial em contextos de pobreza urbana e descrevem, por meio de um trabalho etnográfico, a precariedade das escolas localizadas nesses espaços. A noção de escolaridade no pátio problematiza as tensões que as escolas enfrentam para garantir processos de inclusão. Por fim, as autoras entendem que as lógicas de autogestão e do faça-você-mesmo se tornam formas de inclusão excludente, movendo-se para o interior da escola, onde os professores desenvolvem microestratégias para que, no fazer pedagógico da escola, os corpos em situação de precariedade importem.

No quinto artigo, "Inclusão e Produção da Diferença em Escolas do Campo", Washington Cesar Shoiti Nozu e Marilda Moraes Garcia Bruno, docentes da Universidade Federal da Grande Dourados (UFGD), problematizam os modos pelos quais as diferenças têm sido produzidas em escolas do campo em tempos de inclusão. Por meio de uma investigação etnográfica em três escolas do campo da rede de ensino de educação básica de um município sul-mato-grossense e tendo como sujeitos enunciadores, 25 profissionais da educação, os autores analisam os sujeitos, tempos e espaços que configuram a inclusão nessas escolas e os processos de diferenciação dos sujeitos em escolas do campo, questionando a produção de deficiências em razão de diferenças socioculturais e seus encaminhamentos para os serviços de Educação Especial.

O texto produzido por Pedro Henrique Witchs, da Universidade Federal do Espírito Santo, denomina-se “A Situação Minoritária dos Surdos e sua Vulnerabilidade Linguística na Educação" e problematiza um conjunto de políticas que regulamenta a educação de surdos no que se refere aos usos linguísticos dos 
sujeitos surdos, usando como grade de inteligibilidade o conceito foucaultiano de governamentalidade. A partir disso, o autor afirma que os sujeitos surdos são constituídos como minoria linguística, havendo a fragilidade de sua cidadania, que se relaciona, de forma estreita, à vulnerabilidade linguística.

Para finalizar a discussão proposta no número temático, o artigo "Índice de Funcionalidade Brasileiro Modificado (IF-BrM), Diferenciação e Acessibilidade Curricular", do professor Leonardo Santos Amâncio Cabral, da Universidade Federal de São Carlos, realiza uma análise das premissas da Diferenciação e Acessibilidade Curricular (DAC) no processo de legitimação dos direitos educacionais e de formação profissional das minorias político-sociais. Para o autor, a identificação de pessoas com deficiência configura-se como um importante desafio, pois há uma predominância da perspectiva biomédica nos critérios de avaliação no âmbito das políticas de ações afirmativas. Para tanto, o texto articula a discussão com a apresentação do Índice de Funcionalidade Brasileiro Modificado (IF-BrM), buscando pensar formas de sobrepujar situações de vulnerabilidade desses grupos.

Ao compartilhar os resultados de suas investigações, esse conjunto de autores faz circular conhecimentos que nos fornecem elementos para pensarmos sobre a inclusão e a educação de populações em situações de risco ou vulnerabilidade social. Com isso, acreditamos que tais contribuições podem ser úteis para inspirar novas pesquisas, bem como para dialogar com quem se interessa pelo tema.

\section{REFERÊNCIA}

CARMO, M. E.; GUIZARDI, F. L. O conceito de vulnerabilidade e seus sentidos para as políticas públicas de saúde e assistência social. Cadernos de Saúde Pública, Rio de Janeiro, v. 34, n. 3, p, 1-14, mar. 2018. https:// doi.org/10.1590/0102-311x00101417

Adriana da Silva Thoma ${ }^{\dagger}$ (I.M.)

Betina Hillesheim ${ }^{1, *}$

Organizadoras

$\dagger$.In Memoriam

1.Universidade de Santa Cruz do Sul - Departamento de Ciências da Saúde - Santa Cruz do Sul (RS), Brasil.

*Autora correspondente: betinahillesheim@gmail.com

Editoras Associadas: Daniela Dias dos Anjos e Ana Luiza Bustamante Smolka 